\title{
Are The Statue and The Clay Mutual Parts?
}

\author{
Lee Walters \\ University of Southampton
}

\begin{abstract}
Are a material object, such as a statue, and its constituting matter, the clay, parts of one another? One wouldn't have thought so, and yet a number of philosophers have argued that they are. I review the arguments for this surprising claim showing how they all fail. I then consider two arguments against the view concluding that there are both pre-theoretical and theoretical considerations for denying that the statue and the clay are mutual parts.
\end{abstract}

\section{Introduction}

It's a familiar tale: the statue of a woman and the (portion of) clay from which it is made appear to have different properties, whether these be aesthetic, historical, mereological, modal, or sortal. Hence, by Leibniz's Law, they are distinct objects. ${ }^{1}$ For instance, one might argue that whereas the statue can survive the destruction of some small part of the clay, the clay cannot. And what goes for the statue and the clay, goes for humans and the collections of molecules from which they are composed, and more generally for all artefacts and organisms, and their constituting matter.

\footnotetext{
${ }^{1}$ In what follows I suppress 'portion of', but take 'the clay' as I use it here to refer to a material object, a portion of clay, rather than to some stuff or to a plurality of things.
} 
These arguments, then, lead us to the initially surprising claim that two material objects can coincide. In particular, the above modal considerations support

\author{
Moderate Pluralism: There can be distinct material objects that are coincident at every \\ time (at which they exist). ${ }^{2}$
}

Assuming that Moderate Pluralism is true, we can ask what relations hold between coincident material objects such as the statue and the clay? ${ }^{3}$ Many moderate pluralists claim that the clay constitutes the statue. Some moderate pluralists, notably Cotnoir (2010, 2013, 2016; see also Cotnoir and Bacon 2012), Hawthorne (2006), Hovda (2013), and Thomson (1983, 1988), have argued that the statue and the clay are mutual parts, endorsing

\footnotetext{
${ }^{2}$ Fine (2003: 197-198) distinguishes between spatial and material coincidence: $\mathrm{x}$ and y spatially coincide when they occupy identical spatial regions, whereas they materially coincide when they share identical underlying matter. Fine himself thinks that spatial and material coincidence are independent of one another, for a loaf of bread and the bread from which it is made are materially, but not spatially coincident, whereas a water-logged loaf and the loaf that is water-logged are spatially but not materially coincident (cf. Doepke, 1982: 16). As the example of the clay and the statue shows, we can often ignore the distinction between spatial and material coincidence. I shall flag below where the distinction is important, but the reader can bear in mind that it will be material coincidence that I'll focus on when the distinction matters.

${ }^{3}$ The arguments for Moderate Pluralism have been resisted. One might claim that the difference in our willingness to apply a single predicate to the clay and to the statue does not reveal a difference in the properties they instantiate (Lewis, 1986; Noonan, 1991). Other positions in logical space are available (see Hawley, 2002; Rea, 1997; and Sider, 2001 for surveys). Although I accept the modal argument for Moderate Pluralism, we can bracket the truth of Moderate Pluralism here and consider what relations hold between the statue and the clay, assuming that they are distinct coincident objects.
} 
Mutual Parthood: if $\mathrm{x}$ and $\mathrm{y}$ are distinct coincident objects, then $\mathrm{x}$ is a part of $\mathrm{y}$ and $\mathrm{y}$ is a part of $\mathrm{x}$.

But whilst the former claim is an intuitive description of the case (above I talked naturally of artefacts and organisms, and their constituting matter), Mutual Parthood is, I think, not a natural description of the case and stands opposed to the following two more intuitive views:

No Parthood: if $\mathrm{x}$ constitutes $\mathrm{y}$, then $\mathrm{x}$ is not a part of $\mathrm{y}$ and $\mathrm{y}$ is not a part of $\mathrm{x},{ }^{4}$

and

Constituting Parthood: if $\mathrm{x}$ is the matter that constitutes $\mathrm{y}$, then $\mathrm{x}$ is a part of $\mathrm{y}$, and $\mathrm{y}$ is not a part of $x^{5}$

Defenders of Mutual Parthood, however, claim that their view has numerous advantages. First, Mutual Parthood is claimed to be the only view consistent with an acceptable mereology of coincident objects $(\S 3-\S 5)$, for instance being entailed by

Strong Supplementation: if $\mathrm{x}$ is not a part of nor identical to $\mathrm{y}$, then $\mathrm{x}$ or some part of it does not overlap y,

given an auxiliary assumption, and also, for objects that are spatially coincident, by

\footnotetext{
${ }^{4}$ This is Lowe's (2003) view.

5 This view is defended by Doepke (1982), Fine (2008), Goodman (ms), Gilmore (Forthcoming), Koslicki (2008), and Lowe (2013).
} 
Strong Inclusion: If the space occupied by $\mathrm{x}$ is part of or identical to the space occupied by $\mathrm{y}$, then $\mathrm{x}$ is part of or identical to $\mathrm{y}$.

Second, Mutual Parthood affords a satisfactory explanation of how material objects can coincide and also allows us to give an explication of the constitution relation (§6-§7).

Here I assess the case for and against Mutual Parthood compared to the above two rival views. ${ }^{6}$ But before I do so, let me briefly state three assumptions about parthood that I'll be making. There are many notions of parthood in the literature and so there are multiple ways

${ }^{6}$ These positions do not exhaust the possibilities. First, the converse position of Constituting Parthood is omitted: if $\mathrm{x}$ is the matter that constitutes $\mathrm{y}$, then $\mathrm{y}$ is a part of $\mathrm{x}$, and $\mathrm{x}$ is not a part of $\mathrm{y}$. This view seems particularly implausible and has not to my knowledge been defended in the literature. Second, Constituting Parthood is limited to the matter that constitutes an object. On Doepke's $(1982,1986)$ view we can have a hierarchy of objects with objects at lower levels constituting all of the objects above, so that a single object can be constituted by multiple objects. This is because he thinks that what it is for $\mathrm{x}$ to constitute $\mathrm{y}$ is for $\mathrm{x}$ to have some accidental property in virtue of which y exists. So, the alloy constitutes a piece of alloy in virtue of being unified, and the piece of alloy (and the alloy itself) constitute a statue in virtue of standing in some appropriate intentional-causal relation to an artist. Fine (2003: 206) conceives of constitution differently: "it is not a piece of alloy but only the alloy itself that can properly be said to constitute or make up the statue". In any case, Doepke himself appears to reject the generalization of Constituting Parthood, namely that if $\mathrm{x}$ constitutes $\mathrm{y}$, then $\mathrm{x}$ is a part of $\mathrm{y}$, but $\mathrm{y}$ is not a part of $\mathrm{x}$, because he thinks that a person's body constitutes that person and that a person and their body are mutual parts. Third, the views above other than Mutual Parthood leave open the mereological relations that obtain between coincidents that do not stand in the constitution relation. For example, Doepke (1986) argues that there could be a statue and a landmark, each constituted by the same portion of stone, but neither of which constitutes the other. The possibility of coincidents that do not stand in the constitution relation to one another makes Mutual Parthood even more implausible, I think. 
of understanding Mutual Parthood, but I here want to abstract away from these issues as far as is possible. But I will understand 'part', hence Mutual Parthood, in the following ways.

First, I am using 'part' in what I take to be our ordinary way, so that, prima facie at least, parthood is non-reflexive, although I don't assume that it is irreflexive. I do this because some of the arguments discussed below rest on intuitive considerations. Nothing seems to be lost by initially thinking of parthood as non-reflexive, since we can simply introduce identity explicitly when it is relevant.

Those who take a reflexive parthood relation, $\leq$, as primitive can try to capture our ordinary notion of part in terms of a non-reflexive notion of part, <, defined in one of two ways:

$$
\begin{aligned}
& \text { Non-reflexive Parthood 1: } \mathrm{x}<\mathrm{y}=\mathrm{df}(\mathrm{x} \leq \mathrm{y}) \wedge(\mathrm{x} \neq \mathrm{y}) \\
& \text { Non-reflexive Parthood 2: } \mathrm{x}<\mathrm{y}=\mathrm{df}(\mathrm{x} \leq \mathrm{y}) \wedge \sim(\mathrm{x} \leq \mathrm{y})
\end{aligned}
$$

The statue and the clay cannot be mutual parts in the sense of $<$ defined by Non-reflexive Parthood 2, however, so this definition will not suit our purposes. The sense of $<$ defined by Non-reflexive Parthood 1, however, allows that the statue and the clay are mutual parts $(<)$. But if we accept Mutual Parthood and Non-reflexive Parthood 1, then $<$ is irreflexive and fails to be transitive. ${ }^{7}$

Alternatively, we might take our ordinary notion of part to be a non-reflexive relation not defined in terms of a reflexive one. Following Cotnoir and Bacon (2012: 191), we could take

\footnotetext{
${ }^{7}$ That is, if $\mathrm{x}<\mathrm{y}=\mathrm{df} \mathrm{x} \leq \mathrm{y}$ and $\mathrm{x} \neq \mathrm{y}$, then $<$ is not transitive when $\mathrm{x}$ and $\mathrm{y}$ are mutual parts, since if $\mathrm{x}<\mathrm{y}$ and $\mathrm{y}<$ $\mathrm{x}$, then by transitivity $\mathrm{x}<\mathrm{x}$. But that is clearly impossible given our definition. So $<$ is not transitive.
} 
this relation to be transitive and hence treat it as not irreflexive. A final approach says that, despite appearances our ordinary notion of parthood is in fact reflexive.

Second, as I want to be neutral between the above approaches, I do not assume that parthood is transitive. I do assume, however,

Restricted Transitivity: if $\mathrm{x}$ is a part of $\mathrm{y}$, then for all $\mathrm{z}$ not identical to $\mathrm{y}$, if $\mathrm{z}$ is a part of $x$, then $\mathrm{z}$ is part of $\mathrm{y}$.

This does not beg any questions, since advocates of Mutual Parthood, such as Thomson and Cotnoir, accept Restricted Transitivity.

Third, I shall be using 'part' in a univocal and topic neutral way. This seems to be the way in which most mereologists use the term, but in any case it does not beg the question against pluralists concerning part-whole who think that there are different ways in which one object can be a part of another, e.g. the way in which a pint of milk is part of a quart of milk, versus the way in which the letter type 'c' is part of the word type 'cat'. That is because pluralists like Fine (2010: 580) may define a general notion of parthood in terms of the pluralist's many notions of parthood: $\mathrm{x}$ is a part of $\mathrm{y}$ in the general sense iff $\mathrm{x}$ is in any way a part of $\mathrm{y}$. Moreover, we can distinguish different notions of part when it is important.

Having set out these assumptions, let's examine the initial prima facie case against Mutual Parthood, before we turn to the arguments in favour of this revisionary view. 


\section{The Prima Facie Case Against Mutual Parthood}

As I said above, Mutual Parthood does not seem to be a natural description of coincident objects. If we were asked to list the statue's parts, a natural response would be to list its head, its legs, its other anatomical parts, and its microscopic parts. ${ }^{8}$ If we were reminded that the statue also has parts such as its left half and its right half, we might continue our list to include such parts. But I don't think that the clay (or indeed, the lump of clay) would feature on this continued list. Of course, one reason for this might be that we think of the clay not as a part of the statue, but as all of it. However, for moderate pluralists, that the clay is 'all' of the statue is straightforwardly compatible with the clay being a part of the statue, since the two objects are distinct. Even so, I think our initial verdict is that the clay is not a part of the statue.

Regardless of whether we admit that the clay is a part of the statue, there is no inclination, I think, to say that the statue is a part of the clay. For one thing, although we think that the statue is made out of the clay, we do not think that the clay is made out of the statue. But our notions of parthood and being made out of seem to go hand-in-hand - a whole is made out of its parts after all (cf. Fine, 2010: 560). Moreover, given Restricted Transitivity, and assuming that the statue is a part of the clay, then all of the statue's parts, such as its nose, are also parts of the clay. But, as Baker (2000: 81) puts it:

\footnotetext{
${ }^{8}$ You might deny that a statue of a woman has any anatomical parts. But amongst attested metonymic meaning transfers are those that allow us to use terms that properly apply to things represented to apply to representations. For example, 'Samed is hiding behind the stone lion' even though there are no (real) lions made of stone.
} 
is it obvious that they [the statue David and the clay of which it is made] share all of the same parts? Pretheoretically, I would have thought that David had a nose as a part but that [the clay] did not. Part of [the clay] is (i.e., constitutes) David's nose; but [the clay] itself does not have a nose. Or so I would have thought.

9

To emphasise Baker's point, although the clay has a part that coincides with the statue's nose, the same sorts of reasons that we have for distinguishing between the clay and the statue are also reasons for distinguishing between the nose and the portion of clay that is coincident with it. So, moderate pluralists need not say that the clay has a nose as a part, once this is distinguished from the coincident portion of clay. Moreover, pre-theoretically it seems that the only macroscopic parts of aggregates of macroscopically homeomerous stuffs, such as portions of clay, are themselves aggregates of such stuffs, thus ruling out the claim that such portions have anatomical parts.

The claim that the statue is a part of the clay also conflicts with the following initially plausible claim about parthood

1. If $\mathrm{x}$ is a complex part of $\mathrm{y}$, and we replace a part of $\mathrm{x}, \mathrm{z}$, with $\mathrm{w}$, whilst leaving $\mathrm{x}$ in place and without destroying $\mathrm{y}$, then $\mathrm{x}$ remains a part of $\mathrm{y} .{ }^{10}$

\footnotetext{
${ }^{9}$ See also Doepke (1982: 16), Fine (2003: 198 n5) and Lowe (2003: 157).

${ }^{10}$ Perhaps (1), as formulated, is subject to counterexample, but I think that something in the vicinity is correct, and that Mutual Parthood violates (1), prima facie tells against Mutual Parthood. Here I want to resist arguments for Mutual Parthood, not to consider arguments for other views, but something like (1) underwrites the view that sometimes one coincident is part of another. Pre-theoretically, it might seem that there are three ways for $\mathrm{x}$ to
} 
This is because we could replace, say, the clay nose of the statue with an alabaster one without destroying either the clay or the statue - the clay can survive scattering, and the statue can survive a change of nose. But as the statue is no longer a part of the clay, in virtue of not being completely made of clay, if the statue was a part of the clay before the replacement, then (1) is false.

Finally, if we assume that parthood is transitive, as is standard, Mutual Parthood also yields the unintuitive result that the statue and the clay are parts of themselves (remember that I am not assuming parthood to be reflexive)! In any case, as well as being initially unappealing, the claim that the statue and the clay are mutual parts has at least some revisionary consequences.

In $\S 3-\S 7$, I consider and reject five arguments for Mutual Parthood that can be found in the literature. Moreover, towards the end of $\S 5$, I argue that Mutual Parthood, which is motivated by failures of Extensionality, is not a general treatment of such failures, and that the mereological principle underlying Mutual Parthood is false. We are thus free to hold on to the intuitive picture that rejects Mutual Parthood. In the final two sections I consider arguments against Mutual Parthood. First, (§8), I consider and reject an argument that three dimensionalists cannot accept Mutual Parthood. Second (§9), I argue that Mutual Parthood is

cease to be a part of $\mathrm{y}$ : destroy $\mathrm{x}$, destroy $\mathrm{y}$, remove $\mathrm{x}$ from $\mathrm{y}$. Now, consider the following case. Dion is a man and Theon is that part of him which includes all of his body apart from his left foot. But what happens to the relation between Dion and Theon when we destroy Dion's left foot? Assuming that both survive the foot's destruction, then if our tripartite claim about ending parthood is correct, then after the operation Theon is a part of Dion and coincident with him. 
inconsistent with our intuitive picture of aggregates. As a result, it cannot be a general model of coincidence.

\section{Supplementation}

The main case in the literature for Mutual Parthood claims that it is entailed by mereological principles that we must accept. It should not be presumed at the outset, however, that there a substantive logic of parthood. It may be that given the topic-neutral nature of parthood, there are no or very few principles that are universally applicable to the study of parthood. Moreover, even if we restrict our attention to material objects it is not clear that there is a substantive logic of parthood for such objects. Still, it must be conceded that some principles of mereology look initially compelling. We will consider theoretical reasons that bear on which mereological principles we should endorse in $\$ 5$ below. Here, however, I want to explore an argument for Mutual Parthood that rests on the intuitive plausibility of certain mereological principles.

A standard intuitive principle of mereology is

Strong Supplementation: if $\mathrm{x}$ is not a part of nor identical to $\mathrm{y}$, then $\mathrm{x}$ or some part of it does not overlap y,

where $\mathrm{x}$ overlaps $\mathrm{y}$ iff $\mathrm{x}$ and $\mathrm{y}$ are identical or have some common part.

As has been noted before (Crisp and Smith 2005: 327-8, 334-5, Hawthorne, 2006; Hovda 2013: 257; and Sider, 2001: 155), Mutual Parthood follows from Strong Supplementation 
given the claim that the statue and the clay completely overlap. That is, the claim that every part of the statue overlaps some part of the clay, and vice versa.

One way to see the intuitive pull of Strong Supplementation is to note that it appears to be supported by one natural way of thinking about parthood that I call the inclusion model of parthood. Consider which, if any, of the three blue circles B, C, and D are parts of the white circle with the dashed perimeter, A? Intuitively, B might be a part of A since it is included within A's boundaries (whether it is in fact a part of A cannot be deduced from such a diagram, since B may merely be contained within A, just as a toy might be contained in a box, but assume that B is a part of A). D, on the other hand, is not a part of A, since D is excluded by A's boundaries. C, which is neither included nor excluded by A's boundaries is also not a part of A, although some part of $\mathrm{C}$, the part of $\mathrm{C}$ included by A's boundaries, is a part of A. This type of picture, I think, underlies some of our thinking about parthood, at least for those objects that occupy space.

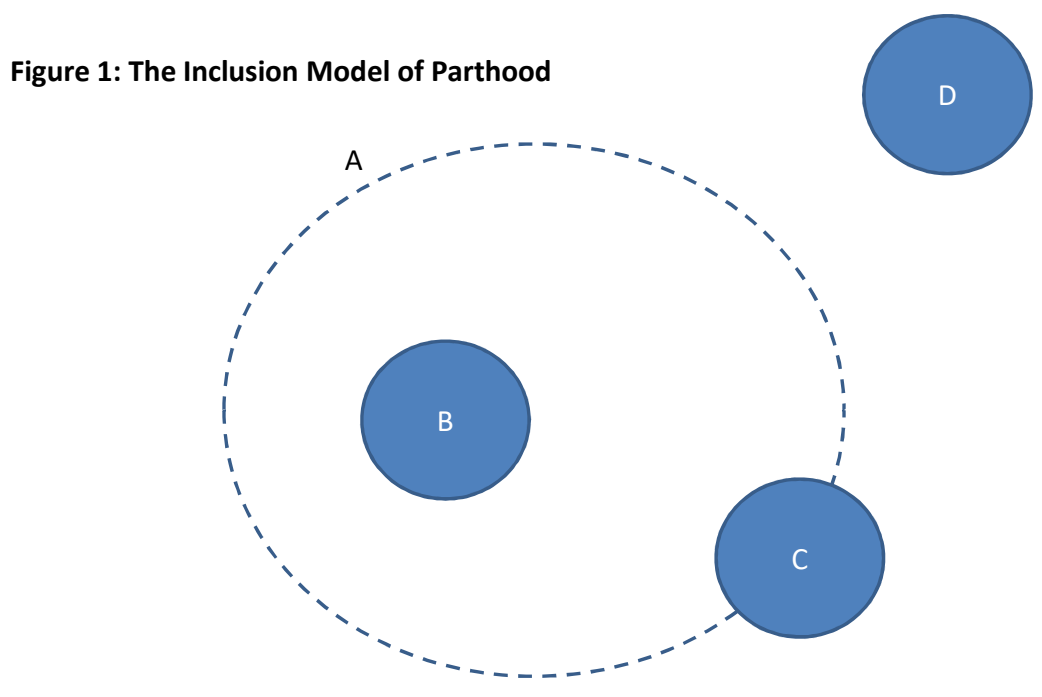


As Fine (2010: 560) puts it,

When one object is a part of another, there is a sense in which it is in the other-not in the sense of being enclosed by the other, as when a marble is in an urn, but more in the sense of being integral to the other.

It is a virtue of Strong Supplementation that it accords with the inclusion model: C and D are not parts of A, and thus have parts that do not overlap A. Contrapositively, B does not have a part that does not overlap A, and so is a part of A. So I think Strong Supplementation captures part of our initial thinking about parthood.

One might accept Strong Supplementation, however, but resist Mutual Parthood by denying that the statue and the clay completely overlap. One way of doing this is to deny that the statue and the clay share any parts: the part of the statue that looks like a small piece of clay or an atom is in fact a distinct thing that is coincident with the piece of clay/atom. This 'duplicate particle' view is not plausible, however. First, pre-theoretically we think that clay statues, as well as having anatomical parts, also have bits of clay as parts - they are made of clay (cf. Wasserman, 2002: 199). Second, whilst there are powerful arguments for pluralism that seem to require us to accept that manipulating some clay brings a statue into existence, we don't think that such activity also brings into existence a host of particles as well (cf. Wasserman, 2002: 199). Relatedly, the arguments that motivate Moderate Pluralism do not extend to such small parts. That is, anatomical parts are not individuated as finely as particles, and so there will be minimal complex anatomical parts that have only bits of matter as parts (see Lowe, 2013). Third, the view is subject to the additivity objection to Moderate Pluralism: if the statue and the clay are distinct and yet both weigh 10 kilos, then when we 
place them on the scales together they should jointly weight 20 kilos, but they don't. Moderate Pluralists who say that the clay and the statue share their matter have a ready-made answer - it is in virtue of having matter that these objects have a weight, so if they share their matter they also share their weight. We do not calculate the weight of an object by adding the weight of all its parts, rather it is by adding the weight of its non-overlapping parts. Similar things can be said for other shared properties of the clay and the matter. Finally, if we deny that the statue and the clay overlap, then we cannot appeal to the sharing of matter to explain coincidence (see $\S 6)$.

A more promising approach to denying complete overlap allows that the statue and the clay share some parts. One way of implementing this strategy would be to claim that whereas the statue lacks any material parts that do not overlap the clay, it does have formal parts that do not overlap the clay (see Fine, 2008; and Koslicki, 2008). If this is combined with the view that the clay does not have such formal parts, then it follows from Strong Supplementation that the clay is a part of the statue, but it does not follow that the statue is a part of the clay. Further, the resulting picture makes good sense: the statue, but not the clay, is a hylomorphic compound of matter and form. So this version of Constituting Parthood, like Mutual Parthood, can hold on to Strong Supplementation. ${ }^{11}$

I want to remain neutral on whether material objects have formal parts, and also on the question of whether Constituting Parthood is the best alternative to Mutual Parthood. So, for the remainder of the paper, let us assume that the statue and the clay completely overlap. Given this, we must either embrace Mutual Parthood, or else reject Strong Supplementation.

\footnotetext{
${ }^{11}$ A second way of allowing partial but not complete overlap consistent with Strong Supplementation and the denial of Mutual Parthood is to posit modal parts (see Graham, 2014; and Wallace, 2014).
} 
But as we have seen Strong Supplementation is an initially compelling principle motivated by the intuitive inclusion model of parthood. As such, it does not appear that we can simply reject the principle. Having said that, if, as I claimed above, Mutual Parthood is itself unintuitive, then we have to give up something that we may, initially, want to hold on to.

In any case, we should be wary of accepting Strong Supplementation. First, before we consider Mutual Parthood itself, Strong Supplementation has the immediate consequence that the statue's head is a part of the clay, which is not obvious. Second, although Strong Supplementation looks good, its contrapositive does not look so good when we consider cases of coincidence: if $\mathrm{x}$ and $\mathrm{y}$ completely overlap, then they are mutual parts. This is one way of giving voice to the unintuitiveness of Mutual Parthood. Moreover, one might think that Strong Supplementation is just too close to the desired conclusion to provide much support for it: anyone not inclined to accept Mutual Parthood will not be inclined to accept Strong Supplementation, and especially its contrapositive, in full generality.

More importantly, another standard intuitive principle about parthood is

Weak Supplementation: if $\mathrm{x}$ is a part of $\mathrm{y}$, then there is some part of $\mathrm{y}, \mathrm{z}$, that does not overlap x.

It is a virtue of Weak Supplementation, like Strong Supplementation, that it accords with the inclusion model: B is a part of A, and thus A has a part - the white bit within the dashed line that does not overlap B. Contrapositively, Weak Supplementation captures the prima facie failure of reflexivity for our intuitive notion of parthood, since A does not have a part which 
does not overlap A, and so A is not a part of A. So I think Weak Supplementation also captures part of our ordinary thinking about parthood.

But given our assumption of complete overlap, No Parthood follows from Weak Supplementation. Moderate pluralists, then, are committed to rejecting at least one of Strong and Weak Supplementation: Mutual Parthood follows from Strong Supplementation but is inconsistent with Weak Supplementation. Vice versa for No Parthood. ${ }^{12}$

It is not clear why the argument from Strong Supplementation to Mutual Parthood and the rejection of Weak Supplementation is in any better standing than an analogous argument from Weak Supplementation to a rejection of Mutual Parthood and Strong Supplementation. Can we break the deadlock? Although Mutual Parthood is not consistent with Weak Supplementation it is consistent with the following restricted version

Weak Supplementation*: if $\mathrm{x}$ is a part of $\mathrm{y}$ and $\mathrm{y}$ is not a part of $\mathrm{x}$, then there is some part of $y, z$, which does not overlap $x$.

Analogously, however, No Parthood (and Constituting Parthood) is consistent with the following restricted version of Strong Supplementation

\footnotetext{
${ }^{12}$ In standard mereologies, Weak Supplementation follows from Strong Supplementation given the asymmetry of parthood: if $\mathrm{x}$ is a part of $\mathrm{y}$, then $\mathrm{y}$ is not a part of $\mathrm{x}$. The mutual parts theorist, however, rejects asymmetry, and so a commitment to Strong Supplementation does not bring with it a commitment to Weak Supplementation. One might take the rejection of asymmetry itself as a reason to reject Mutual Parthood. Fine (2010), for instance, takes asymmetry as an important test of when we have a parthood relation.
} 
Strong Supplementation*: if $\mathrm{x}$ is not a part of nor identical to nor coincident with $\mathrm{y}$, then $\mathrm{x}$ has some part, $\mathrm{z}$, which does not overlap $\mathrm{y}$.

The mutual parts theorist might say, however, that the status of Weak and Strong Supplementation* are not the same. Whereas, Strong Supplementation* concerns some cooked-up relation expressed in its antecedent, Weak Supplementation* does concern an interesting notion. Cotnoir $(2010,2016)$ distinguishes between two notions of proper parthood: non-identical parthood and parthood with remainder, claiming that Weak Supplementation* captures the latter notion.

This response will not convince the Constituting Parthood theorist, for she accepts that the clay is a part of the statue and not vice versa, but denies that there is any remainder, and so rejects Weak Supplementation*. Such a theorist need not deny that there is an interesting notion of parthood with remainder, but only deny that Weak Supplementation* captures this notion. To insist otherwise is to beg the question against Constituting Parthood (see also §5).

But what of the No Parthood theorist who, for all we have said, accepts Weak Supplementation*? Such a philosopher could reply that Strong Supplementation* is in fact telling us about a genuine relation of theoretical interest, the one that is the subject of its consequent, namely, overlap. So, unless more can be said, then as far as these supplementation principles go, there seems to be no reason to accept Mutual Parthood.

We should note, however, that Constituting Parthood (assuming complete overlap) requires the rejection of both Strong and Weak Supplementation (as well as Weak* Supplementation). 
This, perhaps, gives us a reason to reject Constituting Parthood. Constituting Parthood is, however, consistent with the following intuitive principle

Quasi-Supplementation: if $\mathrm{x}$ is a part of $\mathrm{y}$, then $\mathrm{y}$ has two parts, $\mathrm{w}$ and $\mathrm{z}$, such that $\mathrm{w}$ and $\mathrm{z}$ do not overlap,

as are Mutual Parthood and No Parthood.

The three-part inclusion model of parthood above does not distinguish between Strong, Weak, and Quasi-Supplementation, all of them being consistent with that model. What cases of coincidence show, however, is that these three supplementation principles can come apart. And which principles are upheld depends upon how we construe the mereological relation between coincident objects. But given that models of distinct coincidents do not themselves seem to be part of our pre-theoretical thinking about parthood, it is not clear what to say about such cases. So it is not clear which supplementation principles we should accept and reject given cases of coincidence. As a result, it is hard to see how an argument based on the intuitive status of the above supplementation principles could be decisive. There is, then, no quick route from supplementation principles to claims about the mereological relations between the statue and the clay.

We'll return to the above supplementation principles in $§ 5$, but first I want to consider an argument for Mutual Parthood similar to the one above that is presented by Simons (1987: 228-229), and endorsed by Thomson (1998) and Cotnoir (2013). 


\section{Mereological Harmony}

Thomson (1998: 155) claims that the following is true when we limit our attention to material objects:

2. $\mathrm{x}$ is part of or identical to $\mathrm{y}$ iff the space occupied by $\mathrm{x}$ is part of or identical to the space occupied by $y$.

The right-to-left direction of (2) is

Strong Inclusion: If the space occupied by $\mathrm{x}$ is part of or identical to the space occupied by $\mathrm{y}$, then $\mathrm{x}$ is part of or identical to $\mathrm{y}$.

As Cotnoir notes,

There is a natural attraction to the idea that the structure of locations should be in harmony with the structure of parts. [Strong] Inclusion is compelling, I think, because it represents one way in which these structures may be in harmony (2013: 838).

It is natural to think that the structure of locations are in harmony with the structure of a material object's parts, and Strong Inclusion is prima facie attractive, gaining support from the inclusion model of parthood. Mutual Parthood, however, follows from Strong Inclusion and the observation that coincident objects occupy identical spaces. One might, with Fine, (2003: 197-198), deny the latter claim in full generality: perhaps a loaf of bread occupies a region of space that outstrips that occupied by the bread from which it is made, and so neither 
Strong Inclusion nor (2) entails that the loaf is a part of the bread. Still, Strong Inclusion would lead us to conclude that many material coincidents are mutual parts, and this is revisionary enough.

The reply to this argument for Mutual Parthood is essentially the response to the argument from Strong Supplementation. And that this should be so can be seen by taking the contrapositive of Strong Inclusion,

3. If $x$ is not identical to nor a part of $y$, then the space occupied by $x$ is not identical to nor a part of $y$, that is, the space occupied by $\mathrm{x}$ does not completely overlap the space occupied by y,

which is very similar to Strong Supplementation.

First, it follows immediately from Strong Inclusion (without considering issues of Mutual Parthood or Restricted Transitivity) that the statue's head is a part of the clay. Second, Strong Inclusion doesn't seem compelling when we consider cases of coincidence explicitly. Third, to the extent that Strong Inclusion is plausible, it seems to be so in virtue of the fact that it is entailed by the following principles

Proper Inclusion: If the space occupied by $\mathrm{x}$ is part of the space occupied by $\mathrm{y}$, then $\mathrm{x}$ is a part of $\mathrm{y}$.

Spatial Identity: If the space occupied by $\mathrm{x}$ is identical to the space occupied by $\mathrm{y}$, then $\mathrm{x}$ is identical to $\mathrm{y}$. 
But we should note that in cases of coincidence, Spatial Identity is false. As such, we cannot appeal to it in order to underwrite Strong Inclusion. Of course, Strong Inclusion also follows from Proper Inclusion and

Weakened Spatial Identity: If the space occupied by $\mathrm{x}$ is identical to the space occupied by $\mathrm{y}$, then $\mathrm{x}$ is part of or identical to $\mathrm{y}$,

and is in fact equivalent to the conjunction of Weakened Spatial Identity and

Weakened Proper Inclusion: If the space occupied by $\mathrm{x}$ is part of the space occupied by $\mathrm{y}$, then $\mathrm{x}$ is part of or identical to $\mathrm{y}$.

But as we can see, the truth of Weakened Spatial Identity, especially given the falsity of Spatial Identity, is so close to begging the question as to be unconvincing. ${ }^{13}$

Finally, as Cotnoir notes, Strong Inclusion is but one way to ensure harmony. Other ways, consistent with rejecting Mutual Parthood, are given by alternative initially attractive principles, consistent with the inclusion model of parthood

Weak Inclusion: If $\mathrm{x}$ is a part of $\mathrm{y}$, then the space occupied by $\mathrm{y}$ has a part, which does not overlap the space occupied by $\mathrm{x}$.

\footnotetext{
${ }^{13}$ Similar remarks could be made about Strong Supplementation.
} 
Quasi-Inclusion: If $\mathrm{x}$ is a part of $\mathrm{y}$, then the space occupied by $\mathrm{y}$ has two parts, w and $\mathrm{z}$, such that $\mathrm{w}$ and $\mathrm{z}$ do not overlap.

But whereas Mutual Parthood follows from Strong Inclusion, it is inconsistent with Weak Inclusion, and both it and its negation are consistent with Quasi-Inclusion. On the other hand, No Parthood follows from Weak Inclusion, is inconsistent with Strong Inclusion, and it and its negation are consistent with Quasi-Inclusion. Finally, Constituting Parthood is inconsistent with both Strong and Weak Inclusion, although consistent with Quasi-Inclusion.

The three-part inclusion model of parthood does not distinguish between these principles of harmony, all of them being consistent with that model. Coincident material objects show that these three harmony principles can come apart. And which principles are upheld depends upon how we construe the mereological relation between coincident objects. Just as with supplementation principles, there is no quick route from harmony to Mutual Parthood.

\section{Extensionality and the Theoretical Role of Supplementation Principles}

Although the intuitive case for Mutual Parthood from Strong Supplementation fails, Cotnoir (2016) argues that Strong Supplementation provides a theoretical reason for Mutual Parthood. In short, he argues that Weak Supplementation is to be rejected, even accepting No Parthood, but that any mereology that rejects both Weak and Strong Supplementation is inadequate. Therefore, we must maintain Strong Supplementation, and so embrace Mutual Parthood. The conclusion only follows if we grant, as the hylomorphist will not, that the clay and the statue completely overlap. But as I shall argue, even accepting this assumption, Cotnoir's argument for Mutual Parthood fails. 
Cotnoir's argument starts from the observation that coincident objects are putative counterexamples to the following mereological principle

Extensionality: If $\mathrm{x}$ and $\mathrm{y}$ have parts and have all the same parts, then $\mathrm{x}=\mathrm{y}$.

For example, Cotnoir (2010: 397) claims that "it is natural to think that a lump of clay and a statue made from it have all the same proper parts". It will be apparent from $\S 2$ that I disagree, siding with Baker (2000) et al in thinking that the statue has parts, such as its head, that the (lump of) clay does not. But noting this does not get to the heart of the issue, for consider the smallest anatomical part of the statue, $\mathrm{x}$, . Now ask whether $\mathrm{x}$ and the clay that constitutes x falsify Extensionality? Those who embrace Constituting Parthood answer no since the clay that constitutes $\mathrm{x}$ is a part of $\mathrm{x}$, but not a part of itself. But what about those who endorse No Parthood? Since $\mathrm{x}$ has no anatomical parts, its parts only being portions of clay and their parts, $\mathrm{x}$ and its constituting matter share all of their parts and thus do represent a counterexample to Extensionality. ${ }^{14}$

Now, as van Inwagen (1990: 53) notes, Extensionality follows from Strong Supplementation and the asymmetry of parthood, since if $\mathrm{x}$ and $\mathrm{y}$ have all the same parts they are mutual parts by Strong Supplementation, and hence identical by asymmetry. So anti-extentionalist moderate pluralists must reject at least one of Strong Supplementation and asymmetry. Mutual parthood anti-extensionalists deny asymmetry, but hold on to Strong

\footnotetext{
${ }^{14}$ Further putative counterexamples to Extensionality include Doepke's (1986) landmark and statue composed from the same stone, and Fine's (1999) variable embodiments with the same manifestations but different principles of variable embodiment.
} 
Supplementation. But, since other anti-extensionalists reject Strong Supplementation, there is no quick argument from the failure of Extensionality to Mutual Parthood. ${ }^{15}$

Cotnoir (2016), replying to Varzi, argues that there are problems with any anti-extensionalist rejection of Strong Supplementation, and so provides a distinct argument for Mutual Parthood from the failure of Extensionality. Varzi (2009) argues that

\section{Universal Fusion: $\forall \mathrm{xx} \exists \mathrm{y}$ (y is a fusion of $\mathrm{xx}$ )}

entails Extensionality, where we can think of fusions as what Hovda (2009) calls Type-2 fusions: $\mathrm{y}$ is a fusion of $\mathrm{xx}=\mathrm{df}$ every one of $\mathrm{xx}$ is a part of $\mathrm{y}$, and every part of $\mathrm{y}$ overlaps one of xx. Given that we here want to be neutral between moderate pluralists who deny Extensionality and those who don't, we must either resist Varzi's argument or else give up Universal Fusion. Although some moderate pluralists deny Universal Fusion, others are happy to accept it or some similar principle that Varzi could have appealed to instead. ${ }^{16}$

\footnotetext{
${ }^{15}$ Van Inwagen (1990: 53), who himself is not a moderate pluralist, thinks that moderate pluralists should give up Strong Supplementation, and in particular should deny that the statue is a part of the lump of clay coincident with it.

${ }^{16}$ Rejecting Mutual Parthood and accepting certain plenitudinous ontologies leads to a hierarchy of material objects that is hard to reconcile with Universal Fusion. Such hierarchies are consistent, however, with Set-sized Fusion: for any material objects $\mathrm{xx}$ that can be put in a one-to-one correspondence with the members of some pure set, there is a fusion of xx. See Goodman (ms) for discussion. Varzi's argument does not essentially rely on Universal Fusion: Set-sized Fusion and similar principles would suffice. Accepting principles such a Universal Fusion is consistent with thinking that although ordinary material objects are themselves fusions of their parts, they are not unstructured wholes generated by the compositional operation of fusion (see Fine, 2010: 589), that the operation of fusion is "one tiny star in a vast mereological firmament" (Fine, 2010: 576) and that objects generated by the operation of fusion are "a backwater of ontology" (Johnston, 2006: 637).
} 
Cotnoir argues, however, that the only way to be an anti-extensionalist and hold on to principles like Universal Fusion is to accept Mutual Parthood.

Following Cotnoir, we can construe Varzi's argument from Universal Fusion to Extensionality as follows. Take some putative counterexample to Extensionality, $\mathrm{x}$ and $\mathrm{y}$, and consider their fusion, $\mathrm{z}$, which exists by Universal Fusion. $\mathrm{x}$ is a part of $\mathrm{z}$ that violates Weak Supplementation, since there is no part of $\mathrm{z}$ disjoint from $\mathrm{x}$, given the complete overlap of $\mathrm{x}$ and y. But Varzi takes Weak Supplementation to be constitutive of parthood, and so there can be no counterexample to Extensionality assuming Universal Fusion.

The only response for anti-extensionalist pluralists who accept Universal Fusion is to deny the initially compelling Weak Supplementation. But here we are dealing with a case very different from those which guide our ordinary thinking about parthood and which motivated Weak Supplementation. Varzi's case concerns the fusion of a pair of coincident objects that, assuming such fusions are themselves located, are also coincident with their fusion! So, although giving up Weak Supplementation is, perhaps, surprising, we are here considering giving it up in this very odd case. Moreover, the fusion of two coincident objects is not one that we have any pre-theoretic judgments about. So it seems, then, that the anti-extensionalist moderate pluralist can maintain Universal Fusion by giving up Weak Supplementation for the fusions of coincident objects.

We should note that no parthood theorists are now in the same position as constituting parthood theorists in having to deny both Strong and Weak Supplementation, and also both Strong and Weak Inclusion, assuming fusions are located. Furthermore, Cotnoir (2016) argues that we cannot simply deny both Strong and Weak Supplementation, since any such 
mereology is unacceptable. If he is correct, then Constituting Parthood must be rejected, as must any no parthood view that denies Extensionality and countenances the fusion of distinct coincident objects. Mutual Parthood, on the other hand, is acceptable according to Cotnoir, since it validates Strong Supplementation.

Cotnoir argues that in the absence of Weak Supplementation, we need Strong Supplementation to rule out certain possibilities allowed by Quasi-Supplementation. In particular, although Quasi-Supplementation requires that a complex object, $\mathrm{x}$, has multiple disjoint parts, it allows that $\mathrm{x}$ has a part $\mathrm{y}$, such that there is no part of $\mathrm{x}$ disjoint from $\mathrm{y}$. Moreover, there could be a part of $\mathrm{y}, \mathrm{z}$, such that no part of $\mathrm{y}$ is disjoint from $\mathrm{z}$. And so on, as long as there are some parts of $\mathrm{x}, \mathrm{v}$ and $\mathrm{w}$, such that $\mathrm{v}$ and $\mathrm{w}$ are disjoint.

Cotnoir claims that

[t]hese structures seem much more akin to set theory, in which there is a clear difference between e.g. $\{\{\{\mathrm{w}, \mathrm{z}\}\}\}$ and $\{\{\mathrm{w}, \mathrm{z}\}\}$. They are less mereologically sound, and they don't seem to map clearly on to the intuitive gloss that 'an object that has a proper part must have two disjoint proper parts'. In any case, strange models of this sort have nothing to do with failures of extensionality (Cotnoir, 2016: 126-127). ${ }^{17}$

\footnotetext{
${ }^{17}$ Effingham rejects Weak Supplementation on the basis of time-travel cases and like Cotnoir, thinks "[i]t is not good enough to simply cast aside principles like [Weak Supplementation] and carry on regardless. [Weak Supplementation] is introduced to rule out bizarre scenarios" (2010: 337) i.e the sorts of structures considered above. Effingham embraces perdurantism in order to rule out these 'bizarre scenarios'. What I say in the main text in response to Cotnoir applies equally to Effingham's argument for perdurantism (see also $\S 8$ for a discussion of persistence).
} 
We can discern three complaints here. First, Cotnoir states that these structures don't map on to the idea that an object that has a part must have two disjoint parts. Given that QuasiSupplementation does in fact ensure that any object that has a part, has two disjoint parts, and that all the complex objects in the structure described above do have two disjoint parts, Cotnoir is mistaken.

Second, Cotnoir complains that we should not allow such structures as they have nothing to do with failures of Extensionality. But the kind of plenitudinous ontology of material objects posited by e.g. Goodman (ms) leads both to failures of Extensionality and generates the structures that Cotnoir objects too. So at least according to such theories, failures of Extensionality and the allegedly problematic structures are linked. And as we shall see below, there are cases that represent failures of both Extensionality and Strong Supplementation

Cotnoir's final objection to the above structures consists of the unsupported claim that these structures are less mereologically sound. Now we certainly do want to rule out such structures in certain cases, but it is not clear that we should rule them out in general. Consider the following principle

\section{Collapse: $\sum \mathrm{x}=\mathrm{x}$,}

where $\sum$ represents a multigrade compositional operation forming a single whole from any number of parts. When $\sum$ is interpreted as the operation of fusion or summation, then Collapse does indeed hold, and this rules out the sorts of structures that Cotnoir wants to 
avoid for objects generated by the operation of fusion. But that fusion obeys collapse does not entail that all compositional operations do. As Fine puts it,

\begin{abstract}
the operation of summation is one tiny star in a vast mereological firmament, and there is no reason to think of it as possessing better mereological credentials than any of the others. It is indeed distinguished by the fact that it is blind to all aspects of the whole other than the parts from which it was formed. But it is hard to see why sensitivity to structure in the other operations should somehow impede their ability to form wholes (Fine, 2010: 576).
\end{abstract}

Not implausibly, Fine (2010) himself takes the ancestral of set membership to be a parthood relation that does not obey Collapse and so allows for the kind of structures Cotnoir wants to avoid. As Cotnoir provides no argument that such models can't be mereological models we can ignore this complaint.

In any case, maintaining Strong Supplementation and embracing Mutual Parthood is not a general response to failures of Extensionality, and so Cotnoir (2016: 127) is wrong to think that "counterexamples to extensionality ought to be thought of as parts of each other". This is because there are counterexamples to Extensionality that are even less plausibly construed as mutual parts than coincident material objects. For example, take the word types 'on' and 'no'. These appear to have the same parts 'o' and ' $n$ ' and yet there is no inclination to regard these words as parts of each other - for one thing their tokens aren't coincident. One might resist this counterexample, by denying that 'o' and ' $n$ ' are the only parts of these words, saying that 'on' but not 'no' has a part comprised of 'o' and the arch of 'n'. But even if plausible in this 
case, it is not a general response since there are similar counterexamples to Extensionality where the parts of the distinct objects are structured in exactly the same way. For example, consider the letter ' $a$ ' and the word 'a', the two different lexemes that are both written 'bank', or two word-for-word or note-for-note identical, but distinct poems or pieces of music written by causally separated artists (for a sketch and a partial defence of the resultant metaphysics, see Walters, 2013). ${ }^{18}$

Some philosophers will doubt these counterexamples to Strong Supplementation. For example, Dodd (2007) denies that there can be distinct yet indiscernible pieces of music. But such philosophers are mistaken for at least three reasons.

First, as Levinson argues, such artworks may differ with respect to their aesthetic properties, and so, by Leibniz's Law, are distinct works:

A work identical in sound structure with Schoenberg's Pierrot Lunaire (1912), but composed by Richard Strauss in 1897 would be aesthetically different from Schoenberg's work. Call it 'Pierrot Lunaire*'. As a Straussian work, Pierrot Lunaire* would follow hard upon Brahms's German Requiem, would be contemporaneous with Debussy's Nocturnes, and would be taken as the next step in Strauss's development after Also Sprach Zarathustra. As such it would be more bizarre, more upsetting,

\footnotetext{
18 Note that single letter words are also counterexamples to Weak Supplementation (and to Weak Supplementation*), so Varzi's claim that Weak Supplementation is constitutive of parthood need not worry the anti-extensionalist. On some views, persons and their bodies provide another counterexample to Weak Supplementation.
} 
more anguished, more eerie even than Schoenberg's work, since perceived against a musical tradition, a field of current styles, and an oeuvre with respect to which the musical characteristics of the sound structure involved in Pierrot Lunaire appear doubly extreme (Levinson 1980: 64).

Second, Levinson notes that (1980: 68 n12) two artists can produce indiscernible works at different times. For example, suppose A writes, in the sense of 'creates', a poem, P, at time t, and that another poet $\mathrm{B}$, who is causally isolated from $\mathrm{A}$, writes a poem, $\mathrm{P}^{*}$, line-for-line identical to $\mathrm{P}$ at a later time $\mathrm{t}^{*}$. Now $\mathrm{B}$ has exhibited the same creative flair as $\mathrm{A}$, so it is natural to say that B has also created a poem: it is not plausible to suppose that B discovered A's work since the poems were produced independently. So, if we want to preserve the correct creationist thought that $\mathrm{A}$ created $\mathrm{P}$ and $\mathrm{B}$ created $\mathrm{P}^{*}$, then given that $\mathrm{P}$ and $\mathrm{P}^{*}$ were created at different times, and the principle that something cannot be created at two distinct times, $\mathrm{P} \neq \mathrm{P} *{ }^{19}$

Finally, authors and composers can, it seems, rewrite their works, by producing embodiments of the work that differ from previous embodiments with respect to their structural properties. So, artworks can change over time. Consider, then, two novels which are created completely separately and which, although resembling one another, we would unhesitatingly say are distinct. Since these novels can be modified over time by modifying copies or by producing copies that differ from their predecessors, then the two novels can come to converge so that

\footnotetext{
19 To create $\mathrm{x}$ is to bring $\mathrm{x}$ into existence. If $\mathrm{x}$ is brought into existence at $\mathrm{t}$, then, if $\mathrm{x}$ has not gone out of existence between $\mathrm{t}$ and $\mathrm{t}^{*}, \mathrm{x}$ cannot also be brought into existence at $\mathrm{t}^{*}$, for, by hypothesis, it already exists.
} 
they are mereologically indiscernible. And yet, there are still two of them, since if $\mathrm{x}$ is distinct from $\mathrm{y}$ at one time, $\mathrm{x}$ is distinct from $\mathrm{y}$ at all times. ${ }^{20}$

These cases show that not all failures of Extensionality can be treated as cases of Mutual Parthood, and that Strong Supplementation fails in general. ${ }^{21}$ Moreover, the fusion of such indiscernible objects shows that Strong Supplementation fails even for fusions. As such, we cannot appeal to Strong Supplementation to rule out the sorts of structures Cotnoir objects to. If we do wish to rule out such structures in certain cases, we instead have to appeal to the fact that the relevant compositional operation obeys Collapse, or that, for the domain in question, the following principle holds

Quasi-Supplementation*: if $\mathrm{x}$ and $\mathrm{y}$ are disjoint parts of $\mathrm{z}$, then for every $\mathrm{w}$ not identical to $\mathrm{z}$, such that $\mathrm{z}$ is a part of $\mathrm{w}$, then there is a disjoint from $\mathrm{z}$ that is also a part of w.

Mutual Parthood, then, is not a general response to failures of Extensionality. Moreover, Strong Supplementation has to be rejected, and so many of the above considerations for Mutual Parthood simply lapse. None of this shows that the statue and the clay are not mutual parts, but once we reject Strong Supplementation, there is no pressure to construe cases of coincident material objects this way. Of course, Strong Supplementation might hold for material objects and their fusions, but given that this principle is not universally valid, even

\footnotetext{
${ }^{20}$ Gallois (1998) rejects this claim arguing instead for temporary identity. Gallois' revisionary position is untenable, however. See Sider (2001: 165-176) for critical discussion of Gallois.

${ }^{21}$ They also show that positing formal parts is not a general response to failures of Extensionality, although one might posit them in the case of the statue and the clay to account for the grounding problem (cf. Fine, 2008).
} 
for fusions, it must be something special about the composition of material objects that underwrites this claim. But we have been given no reason to think that the composition of material objects is special in this way. Better, then, to retreat to Quasi-Supplementation* or Collapse if we want to rule out the structures Cotnoir finds objectionable. ${ }^{22}$

Let's take stock. Both Strong Supplementation and Weak Supplementation are invalid. Appealing to these principles cannot, then, help us decide upon what mereological relations hold between coincident objects. Weak Inclusion is inconsistent with both Mutual Parthood and Constituting Parthood, and also with the combination of No Parthood and Universal Fusion on the assumption that fusions are themselves located. Strong Inclusion, however, is consistent with only Mutual Parthood, and is not shown to be invalid by considerations of indiscernible distinct artworks, since it is not clear what we should say about their location. So with respect to holding on to intuitive principles, then, Mutual Parthood might be thought to have the advantage. But as we saw in $\S 4$, Strong Inclusion seems too close to Mutual Parthood to provide any support for it. And insofar as we want the structures of material objects and their locations to be in harmony, we can, for all that has been said, ensure that with Quasi-Inclusion. There are no quick, decisive arguments for Mutual Parthood from considerations of supplementation principles, or from related principles of harmony.

\footnotetext{
${ }^{22}$ Cotnoir (2010) also resists another argument of Varzi's (2008) for Extensionality by accepting Mutual Parthood. Varzi's argument, however, rests on the following conjecture: moderate pluralists who distinguish between the statue and the clay based on consideration $\mathrm{C}$, should also distinguish between any of the statue's parts and the underlying stuff based on consideration $\mathrm{C}$ as well. But this conjecture is not well-motivated by Varzi, nor is it independently plausible (see the discussion of duplicate particles in $§ 3$ ). For these reasons, even those who embrace Mutual Parthood should reject Varzi's conjecture.
} 
Still, these are not the only considerations offered in favour of Mutual Parthood. In the next two sections, I'll consider arguments from the explanatory role that Mutual Parthood plays in a moderate pluralist metaphysics of material objects.

\section{Coincidence}

The moderate pluralist thinks that there can be two material objects in the same place at the same time. This claim might be initially surprising because it seems to be in the nature of material objects to exclude one another. The perdurantist explains coincidence in terms of the sharing of parts: when material objects coincide this is in virtue of them sharing temporal parts (see $\S 8$ for a discussion of temporal parts, perdurance, and persistence). Temporary coincidence, then, is temporal overlap, and this is supposed to be analogous to common or garden varieties of partially spatially overlapping objects, such as terraced houses, merging roads, and, perhaps, conjoined twins. Just as these objects overlap spatially in virtue of sharing spatial parts, temporarily coincident objects overlap by sharing temporal parts. This is a virtue of the ontology of temporal parts.

How can the moderate pluralist explain coincidence? First, note that although many moderate pluralists do not embrace an ontology of temporal parts, moderate pluralism is consistent with such an ontology. A moderate pluralist who embraces such an ontology is thus free to explain coincidence in the same way that other temporal parts theorists do. Moreover, unlike perdurantists who deny Moderate Pluralism, those who embrace both temporal parts and Moderate Pluralism can provide the same explanation of cases of permanent coincidence as they do of temporary coincidence, namely, that permanent coincidence is simply a matter of two objects sharing temporal parts. ${ }^{23}$

\footnotetext{
${ }^{23}$ Such a view could not identify material objects with mere sums or sequences of temporal parts.
} 
Despite the availability of this explanation, many moderate pluralists reject it. How can such pluralists explain coincidence? If mutual parts theorists take parthood to be transitive, then they will think that the statue and the clay share all of their parts, and so are mereologically indistinguishable. Such theorists, then, can give essentially the same explanation of coincidence as the temporal parts theorist - coincidence is a case of the sharing of parts:

[the perdurantist thinks that] coincidence is the overlapping of spacetime worms, and thus no more objectionable than overlapping roads. But given mutual parthood, the enduring tree and [the coincident] aggregate [of cellulose molecules] also overlap. Indeed, given mutual parthood the overlap is total. [So here] we have an appealing account of why aggregates and trees do not 'crowd each other out' that appeals to our ordinary conception of when material objects do not compete for space (Sider, 2001: 155-156).

And this explanation carries over to the case of permanent coincidence too. This, then, might be thought a virtue of Mutual Parthood, assuming transitivity.

Can moderate pluralists who reject both Mutual Parthood and temporal parts explain coincidence? As we have seen, it is common for moderate pluralists to deny that coincident objects share all of their parts: the statue but not the clay has anatomical parts. But despite denying that coincident objects share all of their parts, such pluralists, as we have seen, typically claim that they do share all of their parts at some level. That is, coincident macroscopic objects, such as the statue and the clay, share their matter. But given that it is in 
virtue of being material that material objects exclude one another when they do, objects that share their matter need not - could not! - exclude each other (terraced houses share some of their matter, and so do not exclude each other from the regions occupied by their shared matter). So there is no difficulty in explaining how there can be coincident objects, if we admit that such objects share their matter, regardless of whether they share all of their parts. The mutual parts theorist, then, doesn't have any advantage over other moderate pluralists when it comes to explaining coincidence. ${ }^{24}$

\section{Constitution}

As we noted above, some moderate pluralists say that the clay constitutes the statue. If Mutual Parthood allows for a reduction or an elucidation of constitution that is otherwise unavailable, this would provide some reason for accepting this revisionary thesis. It is not clear, however, that such a reduction would be sufficient to motivate Mutual Parthood, since this economy in ideology would come at the cost of revising our ordinary conception of the statue and the clay. In any case, I shall argue that Mutual Parthood has no advantage over its rivals.

The first appeal to Mutual Parthood made in this vein is Thomson's (1983: $218 \mathrm{n} 11)$ attempt at defining constitution:

\footnotetext{
${ }^{24}$ Simons (1987: 228) claims that mereological indistinguishability "makes it easier to explain community of properties [of coincidents], since many physical properties, such as weight, shape, size, colour and volume, are determined by the nature and distribution of a continuant's parts". But these properties are also determined by the nature and distribution of an object's matter, and so coincident material objects are indistinguishable with respect to these properties regardless of whether they are mereologically indistinguishable.
} 
4. $x$ constitutes $y=d f x$ and $y$ are mutual parts. ${ }^{25}$

But whereas the relation of constitution is asymmetric, the relation of mutual parthood is symmetric. What is needed is a way of accounting for the fact that whereas the clay constitutes the statue, the statue does not constitute the clay, and (4) does not provide this. In response to this worry, Thomson (1998: 157) modifies her account of constitution as follows

5. $x$ constitutes $y=d f(a) x$ and $y$ are mutual parts, (b) $x$ has an essential part $z$ such that neither $\mathrm{z}$ nor any part of $\mathrm{z}$ is essential to $\mathrm{y}$, and (c) it is not the case that: $\mathrm{y}$ has an essential part $\mathrm{z}$ such that neither $\mathrm{z}$ nor any part of $\mathrm{z}$ is essential to $\mathrm{x}$.

In order for Thomson's reduction of constitution to be the basis of an argument for Mutual Parthood, there cannot be an equally good reduction of constitution available to those who deny Mutual Parthood. But this has not been established. Moreover, Lowe (2013), who subscribes to Constituting Parthood, provides the following alternative mereological account of constitution:

6. $x$ constitutes $y=d f(a) x$ and $y$ coincide materially, (b) every part of $x$ and $x$ itself is a part of $y$, but not every part of $y$ is a part of $x$, and (c) $x$ and $y$ do not both stand in the foregoing relation to a third object, $\mathrm{z}$ (Lowe, 2013: 146). ${ }^{26}$

\footnotetext{
${ }^{25}$ Here and below we are only interested in material constitution, the putative relation that holds between the clay and the statue.

${ }^{26}$ Whereas Lowe speaks of $\mathrm{x}$ and $\mathrm{y}$ coinciding spatially, I speak of them coinciding materially (see $\mathrm{n} 2$ ). Lowe's (2013) adoption of Constituting Parthood is not well-motivated. Lowe (2003) initially accepting Weak Supplementation, embraced No Parthood. Lowe (2013), however, gives up Weak Supplementation since he thinks that a cat's head can come to be a part of a cat that also coincides with it. But even though we agree with
} 
Let us assume that Lowe's account is extensionally correct, which seems initially plausible assuming Constituting Parthood, because whereas $\mathrm{x}$ is a part of $\mathrm{y}, \mathrm{x}$ is not a part of itself. It then seems that we are free to endorse Lowe's (2003: 157 n20) claim that Thomson 'makes it part of her definition - quite implausibly and unnecessarily, to my mind - that if x constitutes $\mathrm{y}$ at $\mathrm{t}$, then $\mathrm{x}$ is part of $\mathrm{y}$ at $\mathrm{t}$ and $\mathrm{y}$ is part of $\mathrm{x}$ at $\mathrm{t}^{\prime}$. So, for all that has been said, Mutual Parthood has no advantage over Constituting Parthood. No Parthood theorists, however, cannot embrace (6): on such a view anatomically simple objects share all of their parts with their constituting matter. In any case, I shall now argue that anyone can appeal to the benefits of Thomson's account of constitution, not only mutual parthood theorists.

Before presenting her account of constitution above, Thomson (1998: 155) writes that "surely $\mathrm{x}$ constitutes $\mathrm{y}$ at $\mathrm{t}$ only if $\mathrm{x}$ and $\mathrm{y}$ occupy the same space at $\mathrm{t}$ - thus only if $\mathrm{x}$ is part of $\mathrm{y}$ at $\mathrm{t}$ and $\mathrm{y}$ is part of $\mathrm{x}$ at $\mathrm{t}$ ". No Parthood and Constituting Parthood are consistent with Thomson's initial claim, but not her inference from coincidence to Mutual Parthood. Once we notice this, however, we can simply replace Thomson's reference to mutual parts in her definition of constitution with the claim that $\mathrm{x}$ and $\mathrm{y}$ are coincident. Although, given that we are distinguishing between spatial and material coincidence, it is material coincidence that is of relevance here. This, then, gives the following account of constitution:

Lowe that Weak Supplementation is not valid, this alone is not sufficient to motivate Constituting Parthood. Lowe's (6) is certainly better than his previous attempt to define constitution for no parthood theorists (2003: 157, 2013: 131): $x$ is constituted by $y=\mathrm{df} x$ and $y$ coincide spatially and every part of $y$ is a part of $x$ but not every part of $x$ is a part of $y$, since such a definition fails for the smallest anatomical parts of $\mathrm{x}$. But as I argue below, No Parthood is consistent with an account of constitution that is as good as (5) and (6). 
7. $x$ constitutes $y=d f(a) x$ and $y$ are materially coincident, (b) $x$ has an essential part $z$ such that neither $\mathrm{z}$ nor any part of $\mathrm{z}$ is essential to $\mathrm{y}$, and (c) it is not the case that: $\mathrm{y}$ has an essential part $\mathrm{z}$ such that neither $\mathrm{z}$ nor any part of $\mathrm{z}$ is essential to $\mathrm{x}$.

Indeed, Wasserman (2004: 695) gives (7) as Thomson's analysis of constitution. Given (7), we can see that Mutual Parthood plays no essential role in a Thomson-like reduction of constitution.

One might object, however, that whereas Thomson provides a purely mereological reduction, I (and Lowe) have to rely on the notion of material coincidence as well. But material coincidence can itself be elucidated in mereological terms: $\mathrm{x}$ and $\mathrm{y}$ are materially coincident iff (i) $\mathrm{x}$ and $\mathrm{y}$ have material parts, (ii) every material part of $\mathrm{x}$ overlaps some material part of $\mathrm{y}$, and (iii) every material part of y overlaps some material part of $\mathrm{x}$. As a result, the argument from the reduction of constitution fails to support Mutual Parthood. ${ }^{27}$

\footnotetext{
${ }^{27}$ See Wasserman (2004) for a discussion of definitions of constitution. Wasserman objects to Thomson's (5). First, he claims that persons are not identical to their bodies and that bodies constitute persons. But even if we accept that persons are distinct from their bodies, which Thomson (1997) denies, one might claim that persons are constituted only by their matter. Second, Wasserman claims that it is possible for an extended simple to constitute a statue. But if one is a moderate pluralist, as Thomson is, only because statues, but not their matter can change their parts, there would be no reason not to identify the simple and the statue. In any case, the notion of extended simple is not obviously coherent. Sider (2001: 155 n13) objects to (5) on different grounds: "it is not clear that the definition will even apply to all cases of coincidence [for in some cases] the coinciding objects are equally strongly tied to their parts, since they are of the same kind". But here Sider conflates coincidence and constitution. What Thomson is offering is a characterization of constitution, not of coincidence. The kinds of same kind coincidence that Sider points to would only cause problems for (5) if these same-kind coincidents stand in the constitution relation. See Spolaore (2012) for a discussion of same-kind coincidence and further references. The possibility of same-kind coincidents makes Mutual Parthood even more implausible, I think.
} 
Having considered and rejected five considerations in favour of Mutual Parthood, in the final two sections, we'll consider two arguments against Mutual Parthood.

\section{Persistence}

Typically, those who embrace Moderate Pluralism are three-dimensionalists, that is, they say that material objects are 'wholly present' at any moment at which they exist. Fourdimensionalists, on the other hand, say that material objects occupy time in the way they occupy space. Can we make these views more precise? Following Sider (2001: 59), let's offer a characterization of four-dimensionalism in terms of perdurance: ${ }^{28}$

First, say that $\mathrm{x}$ is an instantaneous temporal part (ITP) of $\mathrm{y}$ at $t$ iff (i) $\mathrm{x}$ exists at, but only at, $t$; (ii) $\mathrm{x}$ is part of $\mathrm{y}$ at $t$; (iii) $\mathrm{x}$ overlaps at $t$ everything that is part of $\mathrm{y}$ at $t$. Second, say that x perdures iff for every time $t$ at which $\mathrm{x}$ exists, there is an ITP of $\mathrm{x}$ at $t$.

Three-dimensionalists are then taken to say that material objects endure, that is, to deny that objects perdure in this sense. But can three-dimensionalists give a positive characterization of endurance? Sider argues they cannot. A natural attempt to capture endurance is

Endurance 1: an object, $\mathrm{x}$, endures iff $\mathrm{x}$ lacks ITPs.

\footnotetext{
${ }^{28}$ The main difference between this and Sider's own formulation of perdurance are (i) that I characterize what it is for an individual object to perdure and (ii) that I do so in non-modal terms. I prefer my less committal formulation because it is not clear why modal considerations are relevant to how an object in fact persists, and also because some arguments for perdurance rest on contingencies, thus supporting only a non-modal characterization of perdurance.
} 
Sider, however, argues that Endurance 1 is inadequate. Consider a portion of clay that is moulded into a statue and then instantly destroyed. Sider claims that in such cases endurance cannot be captured by Endurance 1 since, for moderate pluralist endurantists, the clay and the statue are parts of each other, and so the clay has an instantaneous temporal part, namely the statue. Sider thinks the moderate pluralist must accept the mutual parthood of the clay and the statue because of the argument from Strong Supplementation that we discussed and rejected in $§ 3$. Still, Sider's instantaneous statue does mean that Endurance 1 is not a satisfactory account of endurance for mutual parts theorists, since they will accept that the clay has an ITP.

The obvious response for the mutual part theorist is to endorse

Endurance 2: an object, $\mathrm{x}$, endures iff $\mathrm{x}$ lacks an ITP which $\mathrm{x}$ is not itself a part of.

Endurance 2 allows the mutual parts theorist to accept the possibility of Sider's instantaneous statue, but insists that the clay endures since although it has an ITP, it does not have an ITP it is not itself a part of.

There is, however, an apparent problem for the mutual parts theorist: given that an object is coincident with any of its ITPs, Mutual Parthood entails that a material object and any of its ITPs are mutual parts. As a result, Endurance 2 is consistent with an object having temporal parts of the sort the perdurantist posits. That is, Endurance 2 is consistent with our characterization of perdurance. As such, Endurance 2 appears to be an inadequate characterization of endurance for mutual parts theorists. Moreover, Magidor (Forthcoming) 
has used this fact to argue that Mutual Parthood cannot, in general, be an account of coincidence for three-dimensionalists that want to avoid perdurance. One might think, then, that this tells against Mutual Parthood. I shall argue it does not.

Let 'liberalism' be the view that for any set of spacetime points that are occupied, there is a material object that occupies exactly those points. Liberalism entails that there is an instantaneous object located exactly where my desk is. Let's call these objects 'Short Desk' and 'Desk' respectively. Magidor then argues as follows

This model of co-location [Mutual Parthood] will not do for current purposes: if Short Desk is part of Desk at t, then by definition, Short Desk will be an ITP of Desk at t. Generalising, if we combine liberalism with the mutual-parthood model of co-location we get perdurantism (Magidor, Forthcoming).

That is, given liberalism, we are committed to there being, for every moment at which the desk exists, an instantaneous object that is coincident with the desk. But given Mutual Parthood, the desk and these objects will be mutual parts. So for every moment at which the desk exists, it has an ITP. And so, given a Sider-style characterization of perdurance, Desk perdures (it also endures according to Endurance 2). So Mutual Parthood plus liberalism entails perdurance (see also Sider, 2001: 157). The problem for Mutual Parthood is that a liberal three-dimensionalist seems coherent.

How could the mutual parts theorist respond to this argument? Note that they cannot simply give up Mutual Parthood as a general model of coincidence: Short Desk and Desk are mutual 
parts of each other by Strong Supplementation and by Strong Inclusion, the principles that lie at the heart of the mereology of Mutual Parthood. And although we saw that Strong Supplementation was in general invalid, mutual parthood theorists will want to hold on to it, as well as Strong Inclusion, in the case of material objects. So whether objects like Short Desk are parts of Desk or not, Mutual Parthood, it appears, faces problems.

There is, however, something odd about this argument. Hawthorne (2006) is a liberal threedimensionalist who accepts Mutual Parthood. But if the argument above is correct, Hawthorne's position is incoherent. Now Hawthorne realizes that his position entails perdurantism about material objects. Indeed, part of the point of his discussion is to show that three-dimensionalism is consistent with an ontology of ITPs. To maintain consistency, Hawthorne provides an alternative account of three- and four-dimensionalism. ${ }^{29}$ It is controversial whether the sort of account of three-dimensionalism Hawthorne provides is adequate (Giberman, 2014), but we need not settle that here. For liberal mutual parthood theorists can reject four-dimensionalism even when that claim is formulated in terms of ITPs. To see this, consider David Lewis's setting-up of the endurantist/perdurantist debate:

Let us say that something persists iff, somehow or other, it exists at various times; this is the neutral word. Something perdures iff it persists by having different temporal parts, or stages, at different times, though no one part of it is wholly present at more than one time; whereas it

\footnotetext{
${ }^{29}$ We should note that Magidor is aware of this. Magidor is not arguing that liberal three-dimensionalists cannot accept Mutual Parthood. Rather, she is concerned with whether they are committed to perdurance which is her focus. Sider, on the other hand, does appear to endorse the argument from liberalism to four-dimensionalism, because he both accepts Strong Supplementation and a mereological conception of four-dimensionalism.
} 
endures iff it persists by being wholly present at more than one time (Lewis 1986: 202).

Lewis's characterization of perdurance is similar to Sider's, but as Wasserman (2016) has recently reminded us, it is also importantly different. Whereas Sider's formulation is an ontological one, perdurance being characterized in terms of the existence of ITPs, Lewis's is an explanatory one, characterized in terms of persistence in virtue of the having ITPs. The difference can be made clear by noting that it is consistent with Sider's definition, but not Lewis's, to "take facts about temporal parts to be grounded in facts about temporal continuants, rather than vice versa. This would be a view on which temporal wholes are more basic than temporal parts" (Wasserman, 2016: 245 n7).

Further, as Wasserman emphasises, perdurance is supposed to be a theory of persistence, and as such is supposed to explain persistence. But an ontological account of perdurance, such as Sider's does not do this. In any case, for our purposes the point to note is that liberal endurantism combined with Mutual Parthood does not entail perdurance on Lewis's conception, and so Mutual Parthood is still an option as a model of coincidence for the liberal three-dimensionalist. Still, liberal endurantism combined with Mutual Parthood does entail that some enduring material objects have ITPs at every moment they exist, and so in this way, perhaps, do not contrast with perduring events.

I do not think, however, the fact that an object perdures in Sider's sense is a worry for a threedimensionalist. To see this, note that a similar complaint can be levelled against Constituting Parthood. There could, for instance, be an instantaneous portion of clay, in virtue of there being a single instantaneous clay molecule (I'm assuming portions of clay have such parts 
essentially, cf. Thomson, 1998: 156) that is coincident with a statue. According to Constituting Parthood, this statue would then have an ITP, this instantaneous portion of clay. Further, if we accept either that matter is instantaneous or that there could have been a statue that is serially and exhaustively constituted by a sequence of instantaneous portions of clay, then Constituting Parthood entails that such a statue perdures in something like Sider's sense. ${ }^{30}$ Moreover, there is some sense in which the statue persists by having different temporal parts at different times, by being constituted by different instantaneous portions of clay at different times. As such the statue would perdure in Lewis's sense too.

The three-dimensionalist who accepts Constituting Parthood could accept that statues constituted successively by distinct instantaneous portions of matter are four-dimensional but that most ordinary material objects are three-dimensional. But such a conclusion would only be warranted if the characterization of four-dimensionalism in terms of perdurance is adequate, but why think that? Why not, instead, think that these cases represent a counterexample to any account of four-dimensionalism in terms of ITPs? After all, I don't see why anyone should be committed to saying that a statue that is constituted successively by a sequence of instantaneous portions of clay persists in a different way to other statues, even if they do think that the portion is a part of the statue. Rather, given certain theses about parthood, it seems that an account of four-dimensionalism in terms of ITPs fails to capture what was wanted - even accepted that the statue has ITPs, this doesn't seem to settle the question of whether it occupies time in the way it occupies space. So I think it is not an objection to Constituting Parthood that even three-dimensionalists have to allow that some

\footnotetext{
${ }^{30}$ Goodman (ms) argues that perdurantism characterized a la Sider is equivalent to the claim that all matter is instantaneous. Goodman himself rejects the latter claim and hence that material objects in persist, in general, by perduring.
} 
material objects perdure in either Sider's or Lewis's sense. And the same goes for Mutual Parthood.

Thomson (1983: 213) herself, a three-dimensionalist who accepts Mutual Parthood, thinks the ontology of temporal parts is a crazy metaphysic, whether or not such parts are prior to material objects (1983: 211). As a result she will have to reject liberalism, even though she accepts other plenitudinous principles such as Universal Fusion. To be fair, she does already reject liberalism because it means objects keep popping in and out of existence (1983: 213). Nevertheless, she is happy to divide a region of filled space into arbitrary objects, so why not a region of spacetime? As Fine (2006) notes, we need not think of operations that generate objects as always being compositional: there can be decompositional generative operations too one example being the

generative operation, /, of segmentation which, in application to a material thing $\mathrm{x}$ and a spatio-temporal extension $\mathrm{R}$, will result in the restriction $\mathrm{x} / \mathrm{R}$ of the object $\mathrm{x}$ to $\mathrm{R}$ (assuming that there is such an object). Segmentation generalizes the familiar idea of a time-slice or temporal part, the temporal parts of a thing being the special case in which the restriction is to an instantaneous slice of space-time (Fine, 2010: 585; see also Johnston, 2006 on principles of unity and principles of division).

Three-dimensionalists, regardless of their conception of the mereological relations between a statue and its matter, are free to accept such decompositional operations. Nevertheless, moderate pluralists who accept that material objects have temporal parts cannot think of three-dimensionalism in simple mereological terms. But notice, again following Wasserman, 
that neither Endurance 1 nor 2 provides a theory of persistence; these claims do not explain how objects persist. Even if it is true that material objects lack temporal parts, this is not to say how they persist. (Similarly, to deny that material objects perdure in Lewis's sense is not to say how they persist.) So regardless of how moderate pluralists construe the mereological relation between the clay and the statue, they do not yet have a theory of persistence for enduring objects.

Three-dimensionalists could follow Lewis in providing an explanatory conception of endurance: an object endures iff it persists by being wholly present at the times at which it exists. But this raises an important question: what is it to be wholly present? As Wasserman notes, most of the natural answers turn out to be problematic. One approach is just to deny perdurance:

8. $\mathrm{x}$ is wholly present at $\mathrm{t}=\mathrm{df} \mathrm{x}$ exists at $\mathrm{t}$, but not by having an INT at $\mathrm{t}$.

But as Wasserman complains, this leads to a circular non-explanatory conception of endurance, since an object endures iff it persists by being wholly present at the times at which it exists, which by (8) amounts to saying an object endures iff it persists by persisting but not by having temporal parts.

Wasserman concludes that

Rather than trying to formulate endurantism as a theory of persistence, we can instead formulate it as a denial. In particular, we can take endurantism 
to be the view that objects do not persist through time by having different temporal parts at different times (Wasserman, 2016: 248).

No Parthood and Mutual Parthood endurantists are free to adopt Wasserman's suggestion, or instead take 'wholly present' as primitive, taking (8) not as a definition but as a biconditional elucidating 'wholly present', and so offer an explanatory conception of endurance as persistence by being wholly present. Given the possibility of a statue serially constituted by a sequence of instantaneous portions of clay, it is not clear that Constituting Parthood theorists can embrace such an account. But rather than thinking of this as a disadvantage of the view, it seems that one might instead take this to illustrate the inadequacy of capturing the intuitive distinction in terms of ITPs.

The approach here is thus consonant with Fine (2006) who rejects a mereological approach, and takes as primitive the distinction between how material objects are present in space and time. Any scepticism as to the legitimacy of the distinction from the four-dimensionalist can be answered, not in terms of a reductive account of the two types of presence, but rather by arguing, as Fine does, that

there are a number of considerations which strongly suggest that the distinction is to be understood and applied in just the way the 3D-er thinks. Some of these considerations concern our use of locative expressions in ordinary language, some our conception of composite objects, and some our conception of changing composition; and in each case, it is only the 3D-er's point of view that is able to provide a satisfactory account of the phenomena (Fine 2006: 702). 


\section{Mereological Essentialism}

Although considerations of persistence do not tell against Mutual Parthood as a general model of coincidence, it is not clear that Mutual Parthood can give a universal account of coincidence. Consider a statue, $\mathrm{S}$, made of a portion of clay $\mathrm{C}$, at $\mathrm{t} 1$. Let us change the parts of the statue, by adding parts to $\mathrm{S}$, without destroying $\mathrm{S}$ itself, so that at $\mathrm{t} 2 \mathrm{~S}$ and $\mathrm{C}$ are no longer coincident. At $\mathrm{t} 2, \mathrm{~S}$ is not a part of $\mathrm{C}$ because $\mathrm{S}$ has parts that do not overlap $\mathrm{C}$. But if $\mathrm{S}$ is not a part of $\mathrm{C}$ at $\mathrm{t} 2$, then, we might argue, $\mathrm{S}$ was not a part of $\mathrm{C}$ at $\mathrm{t} 1$ because portions of clay have their parts invariantly (and essentially). A modal version of the argument shows that no object that can survive a change in its parts is a part of its constituting matter. As such, Mutual Parthood is false.

The only realistic line of response, I think, is to deny the claim that portions of matter have their parts invariantly and essentially. I don't think this is particularly plausible when we consider the parts of $\mathrm{C}$ that are themselves portions of clay (cf. Thomson's, 1998: 156 Portion of Clay Principle). But the argument above needs something stronger than that and the defender of Mutual Parthood might reply that insofar as we think portions of clay have their parts essentially, it is because we are focusing only on their clay parts. I agree, but this is because we do not think portions of clay have statues as parts in the first place. In any case, could there not be objects that have all of their parts essentially? Traditionally, this is how mere fusions, objects generated by the operation of fusion, have been conceived, I think. .And what independent reason have we for denying that there could be such objects once we accept, with defenders of Mutual Parthood such as Cotnoir, Hawthorne, and Thomson, a 
plenitudinous ontology ? $^{31}$ The advocate of Mutual Parthood, then, must deny our intuitive picture of portions of matter.

\section{Conclusion}

The claim that a statue and its constituting matter are mutual parts lacks any pre-theoretic support, and indeed has counterintuitive consequences. Given this, only the most compelling arguments for Mutual Parthood should convince us to take the view seriously. We have considered five arguments from the literature for Mutual Parthood and found them all wanting. And although we argued that there is no route from considerations of the persistence of material objects to the falsity of Mutual Parthood, we have argued that at least some counterexamples to Extensionality, such as indiscernible poems, require an approach distinct from, and which undermines the arguments for, Mutual Parthood as a model of failures of Extensionality. Moreover, if there are mere fusions that have all of their parts essentially, then Mutual Parthood is false. We are free, then, to stick to our initial reaction that the statue is not a part of the clay that constitutes it, and have provided some theoretical considerations in support of it. ${ }^{32}$

\footnotetext{
${ }^{31}$ Similar remarks could be made concerning Fine's (1999) variable embodiments that are governed by welldefined postulates.

${ }^{32}$ I presented an earlier version of this paper at the University of Southampton, and I am grateful to the audience (my colleagues). Thanks also to Earl Conee, Craig French, Anil Gomes, Nick Jones, Ian Philips, and Kurt Sylvan for comments and discussion. I am especially grateful to an anonymous referee for Noûs for a number of constructive and helpful suggestions that led to significant improvements in the paper. Thanks also to the Central European University's Institute of Advanced Study for a fellowship that provided a most productive environment during the writing of this paper.
} 


\section{References}

Baker, L. R. 2000: Persons and Bodies: a Constitution View, Cambridge: Cambridge University Press.

Cotnoir, A. J. 2010: Anti-symmetry and non-extensional mereology. Philosophical Quarterly 60: $396-405$.

Cotnoir, A. 2013: Strange parts: The metaphysics of non-classical mereology. Philosophy Compass 8: 834-845.

Cotnoir, A. 2016: Does Universalism Entail Extensionalism? Noûs 50: 121-132.

Cotnoir, A. J., and Bacon, A. 2012: Non-wellfounded mereology. Review of Symbolic Logic 5: 187-204.

Crisp, T. and Smith, D. 2005: 'Wholly Present' Defined. Philosophy and Phenomenological Research 71: 318-344.

Doepke, F. 1982: Spatially Coinciding Objects. Ratio 24, 45-60. Reprinted in Michael C. Rea (ed.) (1997). Material Constitution. Maryland: Rowman \& Littlefield.

Doepke, F. 1986: The Trees of Constitution. Philosophical Studies 49: 385-392

Dodd, J. 2007: Works of Music: An Essay in Ontology. Oxford: Oxford University Press. 
Effingham, N. 2010: Mereological Explanation and Time Travel. Australasian Journal of Philosophy 88: 333-345.

Fine, K. 1999: Things and their parts. Midwest Studies in Philosophy 23: 61-74.

Fine, K. 2003: The Non-Identity of a Material Thing and Its Matter. Mind 112: 195-234.

Fine, 2006: In Defense of Three-Dimensionalism. Journal of Philosophy 103: 669-714.

Fine, K. 2008: Coincidence and Form. Proceedings of the Aristotelian Society LXXXII: 101118.

Fine, K. 2010: Towards a Theory of Part. Journal of Philosophy CVII: 559-589.

Gallois, A. 1998: Occasions of Identity. Oxford: OUP.

Giberman, D. 2014: Passing Through: Why Intrinsic-to-a-Time Endurantism Should not Persist. Analytic Philosophy 55: 89-101.

Gilmore, C. Forthcoming: Quasi-supplementation, plenitudinous coincidentalism, and gunk. In Robert K. Garcia (ed.) Substance: New Essays. Philosophia Verlag.

Graham, A. 2014: From Four- to Five-Dimensionalism. Ratio, 27: 14-28.

Goodman, J. ms. Matter and Mereology. 
Hawthorne, J. 2006: Three dimensionalism. In his Metaphysical Essays, Oxford: Oxford University Press, pp. 85-111.

Hawley, K. 2002: How Things Persist. Oxford: Oxford University Press.

Hovda, P. 2009: What is Classical Mereology? Journal of Philosophical Logic 38: 55-82.

Hovda, P. 2013: Tensed Mereology. Journal of Philosophical Logic 42: 241-283.

Johnston, M. 2006: Constitution. In Jackson and Smith (eds.) The Oxford Handbook of Contemporary Philosophy. Oxford: Oxford University Press.

Koslicki, K. 2008: The Structure of Objects. Oxford: Oxford University Press.

Lewis, D. 1986: On the Plurality of Worlds. Oxford: Blackwell.

Levinson, J. 1980: What a Musical Work is. Journal of Philosophy 77: 5-28.

Lowe, E.J. 2003: Substantial change and spatiotemporal coincidence. Ratio 16: 140-60.

Lowe, E.J. 2013: Mereological Extensionality, Supplementation, and Material Constitution. The Monist 96: 131-148.

Magidor, O. Forthcoming: Endurantism vs Perdurantism: A Debate Reconsidered. Noûs. 
Noonan, H. 1991: Indeterminate Identity, Contingent Identity and Abelardian Predicates. The Philosophical Quarterly 41: 183-193.

Rea, M. (ed.) 1997: Material Constitution. Maryland: Rowman \& Littlefield.

Rea, M. 1997: Introduction. In Rea (ed.) 1997, pp. xv-lvii.

Sider, T. 2001: Four-Dimensionalism. Oxford: Oxford University Press.

Simons, P. M. 1987: Parts: A Study In Ontology. Oxford: Clarendon Press.

Spolaore, G. 2012: Not Just a Coincidence: Counter-examples to Locke's Thesis. Thought 1: 108-115.

Thomson, J. J. 1983: Parthood and identity across time. Journal of Philosophy 80: 201-220.

Thomson, J.J. 1997: People and Their Bodies, in J. Dancy (ed.) Reading Parfit. Oxford: Blackwell.

Thomson, J. J. 1998: The statue and the clay. Noûs 32: 149-173.

Varzi, A. 2008: The extensionality of parthood and composition. Philosophical Quarterly 58: $108-133$. 
Varzi, A. 2009: Universalism entails extensionalism. Analysis 69: 599-604.

Wallace, M. 2014: Composition as Identity, Mereological Essentialism, and Modal Parts. In:

D. Baxter and A. Cotnoir, (eds.) Composition as Identity, Oxford: Oxford University Press, pp. 111-129.

Walters, L. 2013: Repeatable Artworks as Created Types. British Journal of Aesthetics 53: 461-477.

Wasserman, R. 2002: The standard objection to the standard account. Philosophical Studies 111: 197-216.

Wasserman, R. 2004: The Constitution Question. Noûs 38: 693-710.

Wasserman, R. 2016. Theories of Persistence. Philosophical Studies 173: 243-250.

Wiggins, D. 2001: Sameness and Substance Renewed. Cambridge: Cambridge University Press. 